\title{
¿Y el Derecho a la Ciudad? Aproximaciones al racismo, la dominación patriarcal y las estrategias feministas de resistencia en Cali, Colombia $^{* *}$
}

\author{
And the right to the city? Approaches to racism, \\ patriarchal domination and feminist strategies of \\ resistance in Cali, Colombia
}

E o Direito à Cidade? Aproximações ao racismo; a dominação patriarcal e as estratégias feministas de resistência em Cali, Colômbia

\footnotetext{
* Licenciada en Educación Artística, CENDA, estudiante del programa de Maestría en Educación Énfasis en Educación Popular y Desarrollo Comunitario en la Universidad del Valle. Investigadora asociada al Centro de Estudios Afrodiaspóricos (CEAF) de la Universidad Icesi. Correo electrónico: vicentamh@yahoo.es

** Estudiante de la Escuela de Trabajo social de la Universidad del Valle. Investigadora asociada al Centro de Estudios Afrodiaspóricos (CEAF) de la Universidad Icesi. Correo electrónico: dermbayo3@hotmail.com

${ }_{* * *}$ Este artículo de investigación es resultado de estudios realizados por el grupo de Investigación Interseccionalidades que hace parte del Centro de Estudios Afrodiaspórico (CEAF) de la Universidad Icesi y la Asociación Casa Cultural El Chontaduro Cali, Colombia. Artículo recibido el 10/03/2015 y aceptado el 07/07/2015.
} 



\section{Resumen}

Abstract

Resumo

Este artículo busca dar visibilidad a algunas estrategias espaciales de resistencia desarrolladas por mujeres negras del Distrito de Aguablanca (DA), en el Oriente de Cali, Colombia, frente a la violencia sistemática a la que se ven diariamente sometidas. Contextualizamos estas violencias sistemáticas como producto del destierro, el paramilitarismo y la segregación espacial en la ciudad. Se busca también discutir cómo las mujeres negras resisten a la estigmatización, la marginación política y la muerte en una ciudad racialmente dividida. Las preguntas que orientan este articulo son: ¿Cuál es el papel del racismo y la dominación patriarcal en la producción de las "geografías de la violencia" en Cali? ¿Cuáles son las estrategias de resistencia desarrolladas por las mujeres negras en estas topografías de la violencia? En últimas, el artículo busca contraponerse a las narrativas académicas y discursos políticos que criminalizan la vida de la gente negra en los sectores populares y que generalmente presentan a las mujeres negras solamente como víctimas, o como desorganizadas y apolíticas.

\section{PALABRAS CLAVE:}

Dominación patriarcal | interseccionalidades | relaciones raciales | resistencia de mujeres negras | derecho a la ciudad

This article seeks to give visibility to some spatial strategies of resistance developed by black women in the predominantly black district of Aguablanca District (DA), in eastern Cali, Colombia, against the systematic violence they are daily subjected to. We contextualize their practices within the systematic violence of displacement, paramilitaries terror and spatial segregation in the city. It also seeks to discuss how black women resist stigma, political marginalization and death in a city divided along racial and gender lines. The questions that guide this article are: What is the role of racism and patriarchal domination in the production of "geographies of violence" in Cali? What are the strategies of resistance developed by black women in these topographies of violence? Ultimately, the article seeks to fulfill a gap in academic discourses that silence on black women's social suffering and that regard them as disorganized, a-political and passive victims.

\section{KEYWORDS:}

Patriarchal domination | interseccionalities | racial relations | black women's resistance | right to the city 
Este artigo procura dar visibilidade a algumas estratégias espaciais de resistência desenvolvidas por mulheres negras do Distrito de Aguablanca (DA), no Oriente de Cali, Colômbia, diante da violência sistemática à qual diariamente estão submetidas. Contextualizamos estas violências sistemáticas como produto do desterro, o paramilitarismo e a segregação espacial na cidade. Busca-se também discutir como as mulheres negras resistem à estigmatização, à marginação política e à morte em uma cidade racialmente dividida. As perguntas que orientam este artigo são: Qual é o papel do racismo e da dominação patriarcal na produção das "geografias da violência" em Cali? Quais são as estratégias de resistência desenvolvidas pelas mulheres negras nestas topografias da violência? Resumindo, o artigo busca opor-se às narrativas acadêmicas e discursos políticos que criminalizam a vida dos negros nos setores populares e que geralmente apresentam às mulheres negras somente como vítimas, ou como desorganizadas e apolíticas.

\section{PALAVRAS - CHAVE:}

Domínio patriarcal | Interseccionalidades | Relações raciais | Resistência de mulheres negras | Direito à cidade 


\section{Introducción}

El artículo busca dar visibilidad a las vivencias y prácticas espaciales de mujeres negras del Distrito de Aguablanca, así como a su lugar de sujetas activas, ya que se enfrentan al poder hegemónico patriarcal que les niega el derecho a la ciudad. Aunque el artículo se enfoque en la discriminación de clase, raza y de género, también analiza lo que María Lugones (2011) ha llamado "subjetividades resistentes": las mujeres negras construyen sentidos propios en sus territorios, aunque generalmente sus acciones no sean leídas de esa manera; como lo plantea la autora al analizar las relaciones entre opresores y oprimidos:

A la subjetividad resistente se le niegan legitimidad, autoridad, voz, sentido y visibilidad. La infra-política marca el giro hacia dentro, en una política de resistencia, hacia la liberación, y muestra el poder de las comunidades de los oprimidos al constituir significados resistentes y al constituirse entre sí en contra de la constitución de significados y de la organización social del poder. En nuestras existencias colonizadas, generizadas racialmente y oprimidas, somos también otros/otras de lo que el poder hegemónico nos hace ser (2010: 109).

María Lugones reconoce las prácticas de las comunidades oprimidas más allá de una línea plana de víctimas y victimizados, dándoles un lugar de sujetos políticos, en donde se generan resistencias y nuevas construcciones de significados, distintas a las implantadas por el poder hegemónico. Reconoce el poder de las comunidades oprimidas como posibilidad de liberación y trasformación de sus realidades, y no simplemente como un resultado óptimo del opresor ante sus oprimidos. En este artículo nosotras expandimos el concepto de "subjetividades resistentes" señalado por la autora, añadiendo una visión interseccional que muestra cómo la racialización del cuerpo, el género y la clase se interceptan no sólo en la producción de las vulnerabilidades en los territorios de la violencia en Cali sino también en la producción de dichas subjetividades.

El artículo está organizado en cuatro partes. En la primera, presentamos una breve contextualización de las condiciones sociales de los afrodescendientes en la Ciudad de Santiago de Cali; basados en datos oficiales sobre pobreza, empleo y violencia homicida, presentamos la geografía social en la que la vida urbana negra es desvalorizada. En la segunda parte, basadas en el trabajo etnográfico en un barrio popular del Distrito de Aguablanca, presentamos un análisis de las estrategias de resistencia desarrolladas por las mujeres afrodescendientes frente al fenómeno de la violencia urbana en Cali. A partir de entrevistas con madres de jóvenes asesinados por grupos pandilleros o por la policía presentamos una interpretación de cómo las categorías identitarias de raza, de género y clase no pueden ser entendidas sin una consideración del territorio, que no es solo el espacio político donde las dominaciones acontecen, sino también y principalmente un 
medio de producción social; es decir, el espacio urbano es socialmente producido en los encuentros cotidianos de la gente con la fuerza política (Lefebvre 1969; Harvey 2003).

En la tercera parte presentamos entrevistas con mujeres empleadas domésticas en las casas de las élites caleñas. Las entrevistas sugieren que las mujeres negras siguen ocupando en Cali (como en otros contextos de la diáspora africana) el papel subalterno de sirvientas para las élites blancas (Posso 2008; Carneiro, 1990; Alves y Vergara, forthcoming). En la cuarta parte, el artículo termina haciendo un llamado para futuras investigaciones sobre el papel del racismo y de las discriminaciones de género en la producción de la ciudad de Cali como una ciudad desigual.

Aunque el artículo presente solamente las primeras aproximaciones de una investigación exploratoria, que esperamos continuar, ojalá contribuya para desvendar el patrón de dominación racial y patriarcal que roba vidas, explota el cuerpo femenino negro en las cocinas de las élites locales y divide el territorio por medio de políticas de seguridad que siembran el terror en las comunidades marginadas.

\section{El Distrito de Aguablanca}

Según datos del Programa de Política para Promover la Igualdad de Oportunidades para la Población Negra (Conpes 3660) ${ }^{1}$, el Valle del Cauca es el departamento de Colombia que recibe la mayor cantidad de población negra desplazada, correspondiendo a 13.088 familias y 61.039 personas. Así mismo, Cali es la segunda ciudad en América Latina con mayor cantidad de población negra, después de Salvador de Bahía en Brasil; datos del DANE (2005) indican que el 70\% de la población negra en Cali habita en el sector del Distrito de Aguablanca (comunas 13, 14 y 15) y en las comunas 16 y 21 que constituyen la franja oriental de la ciudad (ver mapa 1).

Esta zona que en sus inicios era utilizada para siembras de millo y maíz, o como lotes de engorde ${ }^{2}$ de familias hacendadas de la ciudad, a finales de los años 6ocomienza a ser poblada por personas con distintas situaciones de marginalidad; algunas que siendo habitantes de la ciudad durante más de 20 años no tenían garantizada una vivienda propia, otras que llegaron en busca de refugio por catástrofes naturales como la de Armero en 1985, el maremoto de Tumaco en 1979 y otros que fueron desterrados ${ }^{3}$ por

1. Conpes 366o. Política para Promover la Igualdad de Oportunidades para la Población Negra, Afro-colombiana, Palenquera y Raizal. 2010.

2. Terrenos baldíos cuyos dueños los guardan para revalorizarlos con el tiempo.

3. Santiago Arboleda refiere este término para denotar la manera abrupta de sacar de sus territorios a un grupo de personas o comunidades sin opciones de regreso, lo cual implica fracturas culturales, muertes, desarraigos. Para él esta situación es distinta a un desplazamiento, al cual determina como posibilidad voluntaria de trasladarse de un lugar a otro por distintas causas pero con la posibilidad de regresar. 
la violencia producida por actores armados en territorios ancestrales y campesinos, siendo la población negra de la región del Pacífico la más afectada por dicha situación. A pesar de la diversidad étnica y cultural que lo constituye, desde sus comienzos este territorio ha sido habitado mayoritariamente por población negra oriunda o procedente del Pacífico (Arboleda 1998 y Urrea 2011).

\section{MAPA 1 Distrito de Aguablanca}

\section{Santiago de Cali}

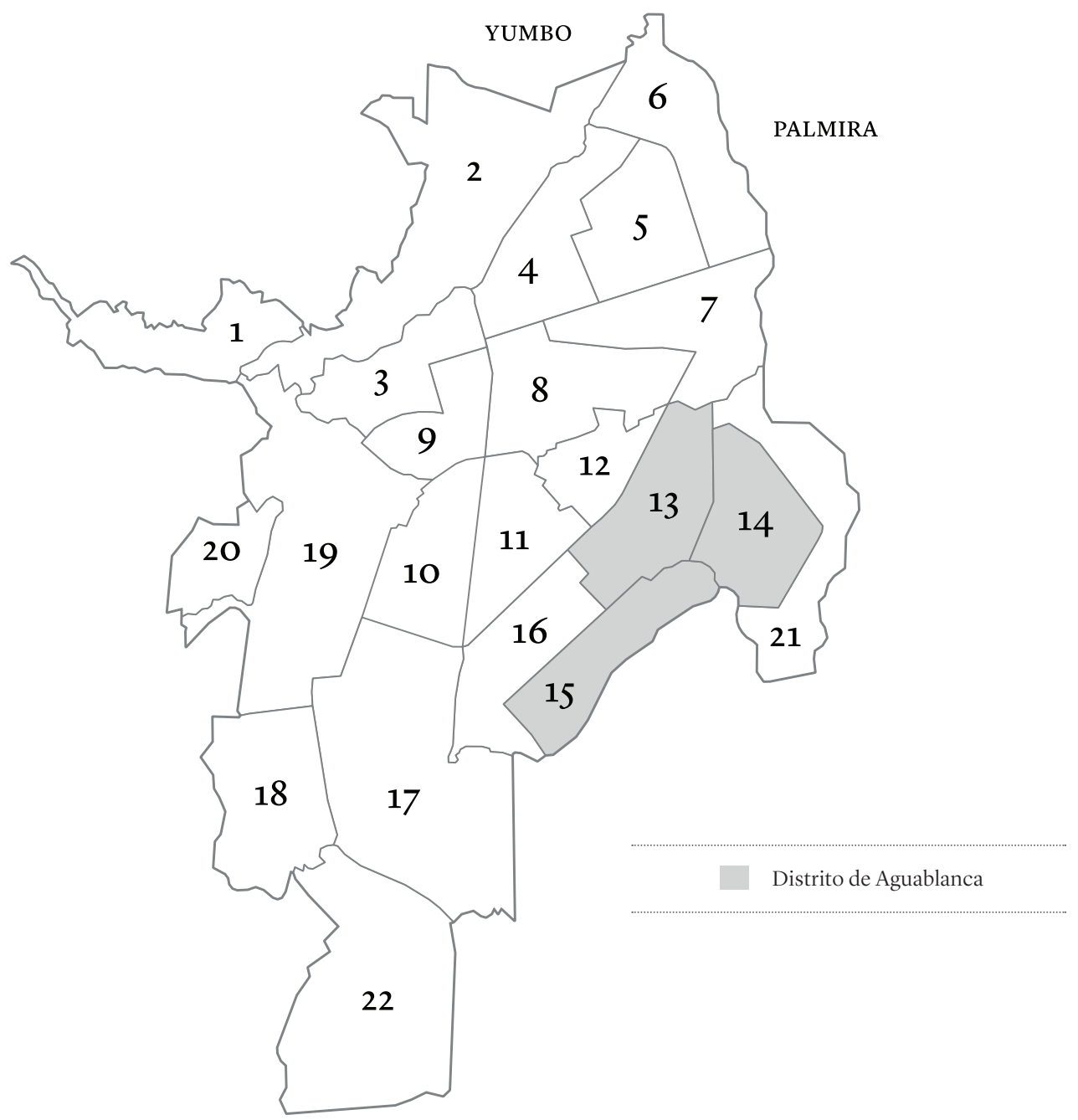


Este sector estaba catalogado poco apto para vivienda por sus características húmedas y fangosas, sin embargo, ante la falta de alternativas de planeación municipal para solucionar los problemas de vivienda que se acrecentaban en la ciudad, la gente empezó a habitarlo construyendo asentamientos, barrios y urbanizaciones ilegales, al mismo tiempo que auto-gestionaban servicios básicos como agua, energía, pavimentación, espacios comunitarios y educativos. Así lo muestra el testimonio de Leticia, una mujer negra de aproximadamente 65 años de edad, procedente de Barbacoas, Nariño, que estudió hasta tercero de primaria, y desde 1982 es habitante del barrio Marroquí III, donde actualmente habita con su compañero, dos hijas, tres nietos y dos nietas, su casa es de ladrillos sin repello, construida hasta la mitad. Entre el comienzo y mitad del 2013 asesinaron a dos de sus nietos jóvenes a causa del conflicto de las fronteras invisibles y enfrentamientos con la policía. Ella manifiesta:

\begin{abstract}
"Yo, antes de llegar al barrio, vivía en el Rodeo con mi marido que en ese tiempo trabajaba la construcción y mis cinco hijos. Allá pagábamos arriendo, yo trabajaba en una casa de familia en el sur y tenía mi platica reunida, disque pa' cuando mi marido se quedara sin trabajo mis hijos no fueran a pasar hambre. Ve, cuando mi prima Eleodora me dijo que estaban vendiendo lotes por acá, yo me vine a las reuniones que hacían en una casa grande de madera, con un señor Marroquín, él fue que nos vendió el lote en treinta mil, que en ese tiempo era una platica, uno tenía que dar quince mil de una, yo no tenía todo eso y la patrona me prestó el resto. Hicimos una ramada de esterillas y esto era un barrialero que cuando llovía nos tocaba salir con chuspas en los pies pa' no embarrarnos los zapatos, pero ve, con toda y esa uno salía embarrado. El agua la íbamos a traer de allá del control del Azul Plateada y nos alumbrábamos con velas. El agua y la luz nosotros mismos las metimos a las casas, porque acá no había nada de eso.” 4
\end{abstract}

Leticia, al igual que otras habitantes del barrio, da cuenta de las condiciones de opresión implantadas a las personas de este sector, pero también muestra cómo le fueron dando vida a ese terreno poco apto para vivir. Todavía la gente de esta zona sigue luchando por una vida digna en esta ciudad que les niega el derecho espacial y las sumerge en constantes violaciones de Derechos Humanos. El trabajo informal es la única posibilidad de empleo para más del 60\% de la población, y la mortalidad infantil y materna inciden de manera preferencial sobre la población de estos territorios. ${ }^{5}$

A la combinación explosiva de distintas formas de violencia (económica y simbólica) se suma la violencia homicida que afecta al Distrito de manera especial, como se percibe en la situación de Leticia, quien a sus 65 años, además de trabajar como empleada doméstica, en un mismo año ve morir a sus nietos a causa de la violencia. Según inves-

4. Entrevista realizada a Leticia en el proceso de estudio del grupo Interseccionalidades, 2015.

5. Ver Plan de Desarrollo, municipio de Santiago de Cali, 2011-2012, p. 79. 
tigaciones, en Cali por lo menos el 30\% de los 339 barrios caleños están bajo el control de alguna de las 134 pandillas que hay en la ciudad. ${ }^{6}$ Los homicidios se mantuvieron constantemente altos a lo largo de la década, siendo los barrios de la ladera y del oriente los que concentran las principales tazas de muertes violentas. De los 1.480 homicidios ocurridos en Cali en los primeros nueve meses de 2013, el 52\% ocurrió en los barrios que componen el oriente de la ciudad, según datos de fuentes oficiales. ${ }^{7}$

Según los relatos de las habitantes del sector, la violencia que azota al Distrito de Aguablanca ha tenido un matiz distinto en cada periodo, y ellas también la enfrentan de diferentes maneras, conservando algunos elementos de la sabiduría ancestral. En los años 80 los niños, niñas y jóvenes del sector no estaban involucrados en dinámicas de violencia, los actores armados no eran de la comunidad. Nataly, mujer negra de 40 años, habitante de Marroquín III desde 1982, tiene una hija de 21 años y un hijo de 24, una nieta y un nieto con quienes convive, junto con su compañero y su nuera, terminó el $11^{\circ}$ grado de educación secundaria y es ama de casa. Ella cuenta:

\begin{abstract}
"Yo fui de las primeras que llegaron a este barrio cuando estaba comenzando, todos los muchachos de por acá eran sanos, pero me acuerdo que por las noches nosotros estábamos dormidos y se formaba la balacera, eso era por allá, más que todo por ese barrio de La Paz, decían que era la guerrilla con el ejército que se enfrentaban, eso habían unas partes donde hacían unas pistolas hechizas. Como mi papá y mi mamá se iban a trabajar todo el día, nosotras nos quedábamos en la casa de Carmen, al lado de mi casa, porque ella era la más adulta de las jóvenes de la cuadra que se quedaban en la casa cuando los papas se iban a trabajar, entonces allí se quedaban un poco de muchachos y ella nos contaba historias y nos cuidaba y nos defendía cuando los más grandes nos querían pegar. Y cuando se armaban las balaceras, todos estábamos allí con ella. Yo me acuerdo que siempre nos quedábamos hasta tarde jugando, pensando bobadas y contando historias, y lo que más me gustaba era que los domingos o festivos entre los vecinos nos ayudábamos a arreglar los techos o las casas y no nos cobrábamos, así se hicieron casi todas las casas de por aqui."
\end{abstract}

Las solidaridades han sido unas de las estrategias más fuertes para resistir la violencia en sus diferentes manifestaciones, generando identidad, construcción colectiva y lazos comunitarios. En los años 90 los actores armados empezaron a integrar a jóvenes y niños a sus dinámicas de guerra, convirtiéndolos al mismo tiempo en víctimas y victimarios. Como resistencia a esta violencia se generó un gran movimiento de redes

6. En Cali existen a la fecha un total de 134 pandillas localizadas en 17 de las 22 comunas de la ciudad, con un total aproximado de 2.134 jóvenes vinculados a estos grupos. Ver personería de Santiago de Cali, informe actual sobre el estado de las pandillas en la ciudad de Cali. Pág. 6. Ver también la criminalidad, el peor indicado de Cali, http:// elpueblo.com.co/la-criminalidad-el-peor-indicador-de-cali/\#ixzz2kqXEFQks acceso 1/ 12/ 2013

7. Notas preliminares para un análisis interseccional de la violencia en el Distrito de Aguablanca. Revista CIES N ${ }^{\circ}$. Editorial Centro de Investigaciones CIES. Centro de Estudios Afrodiaspóricos CEAF. Cali- Colombia. Mayo 2014 
sociales, culturales y artísticas en el Distrito, algunas con bases políticas de educación popular, otras desde lo étnico racial o el género y algunos camuflados haciendo juego a opciones bipartidistas del momento. A partir del año 2000 los casos de asesinatos infantil y juvenil hacia los varones y violencias contra las mujeres se acentuaron mucho más que en la década anterior, las fronteras invisibles encarcelaban cada vez más a los jóvenes en sus propios espacios, reduciéndoles la posibilidad de movilidad y a la vez produciendo inestabilidad a las familias, que permanentemente debieron cambiar de vivienda para proteger a los y las jóvenes. No solo son cercados en sus propios territorios, sino que también se encuentran con barreras para el acceso a otros espacios de la ciudad; los y las jóvenes manifiestan que cuando se desplazan en grupos a algunas zonas de privilegio de la ciudad, son perseguidos o mirados como criminales. A esa situación se suma el destierro de las comunidades ancestrales, que nunca ha parado: en estos momentos los feminicidios y masacres en Buenaventura son ejemplo de ello.

Marroquín III es uno de los barrios a donde llega gran parte de la población desplazada; las mujeres constituyen el mayor número. Es así como las estructuras de la ciudad niegan el derecho a la movilidad espacial de esta población, a la vez que la gente crea permanentemente sus propias dinámicas para hacer más cercana y apropiar la ciudad que les discrimina.

Aunque la violencia homicida afecta principalmente a los jóvenes del sexo masculino, las mujeres negras también sufren sus consecuencias. Una de las manifestaciones de la violencia física, económica y simbólica en la vida de las mujeres del Distrito de Aguablanca puede ser identificada en las condiciones socio-económicas en que viven. En Cali, ser mujer, pobre y negra es estar sometida a una multiplicidad de violencias de las cuales el empleo doméstico es una de las manifestaciones más visibles: según datos oficiales, Cali es de las ciudades con más empleadas domésticas del país. Aunque sean estadísticas poco confiables, ellas muestran que en la ciudad hay 17.304 mujeres oficialmente registradas como empleadas domésticas. ${ }^{8}$ Estos datos revelan, no que hay pocas mujeres en el empleo doméstico, sino que hay precariedad de acceso a sus derechos laborales. La mayoría de las empleadas domésticas no posee vínculos laborales formales, debido a su condición de subordinación en la ciudad.

\section{¿A quién le duelen nuestros muertos?}

Una de las manifestaciones más crueles del racismo en Cali es el robo de los años de vida de los jóvenes negros. Aunque el homicidio entre jóvenes no puede ser adjudicado solamente a las fuerzas policiales del Estado, el Estado cumple un papel determinante 
en la producción de las vulnerabilidades a la muerte prematura en el Distrito (Alves y Vergara, forthcoming; Moncada, 2011). Las mujeres negras aparecen en este contexto como sujetos políticos que no solamente denuncian las políticas de la muerte, sino que también utilizan su identidad territorial (como mujeres negras del oriente) para resignificar su experiencia urbana. En el marco de este proceso de investigación, hemos identificado una serie de respuestas colectivas que visibilizan estas estrategias espaciales.

Una de estas estrategias es la ocupación de espacios públicos para reclamar a los hijos muertos, denunciar la violencia y politizar la muerte. En uno de estos encuentros, en noviembre de 2013, después de varios conversatorios con madres, familiares y vecinas de jóvenes asesinados, las mujeres organizaron un acto performático (ver imagen 1). Aproximadamente 200 personas, entre ellas madres, familiares y vecinas de jóvenes asesinados, caminaron con sus rostros pintados, con sus instrumentos musicales, sus vestuarios de danzas y de personajes teatrales. Pasaron por las calles de dos barrios divididos, calles separadas por fronteras invisibles que condicionan la movilidad de los habitantes entre un sector y otro, ese día fueron ocupadas por un uso estratégico y creativo del espacio. Los cuerpos de las mujeres se convirtieron en vehículos que mediaban las interacciones entre vecinos apartados por el miedo. Toques sonoros de instrumentos musicales le cantaron al viento, implorándole que acompañe siempre la movilidad de los jóvenes por las distintas calles de sus barrios, sin que estos corran ningún peligro. Algunas mujeres bañaron sus cuerpos simbólicamente, como un acto de reclamación de su autoridad ante sus territorios: el agua les servía para alivianar el dolor y fortalecer sus capacidades de creadoras de vida. Ellas, con sus cuerpos productores de vida desafiaban, en las calles, la autoridad del Estado productor de muerte. Bailarinas y Bailarines llevaron antorchas encendidas simbolizando la recuperación del fuego como dador de luz y de vida. Teatreros y Teatreras proclamaron la dimensión de la diversidad humana, diferenciados por distintos matices de formas y colores, pero hijos de la misma tierra y el mismo cosmos.

Al final de una calle, los artistas plásticos esperaban a los caminantes con una valla que decía; "¿A quién le duelen nuestros muertos?: Que el dolor de las madres traspasen las fronteras" (ver imagen 2). Estaba colgada en lo alto, atravesando la calle de lado a lado. En un tendedero se expusieron fotografías de los jóvenes asesinados durante los últimos dos años en los dos barrios; las velas formaban una espiral en el suelo. Entonces cantó Jovilia, una mujer negra de 85 años, proveniente de Tumaco (Nariño).

Desde su llegada a Aguablanca, hace unos 34 años, se desempeñó en el trabajo doméstico, tanto en su propia casa, como en otras casas de Cali. Madre de dos hijas y de un hijo, quienes actualmente la apoyan y sostienen económicamente. Jovilia tomó el micrófono para cantar los alabaos a los jóvenes asesinados., y la calle central que a lo largo de los años ha sido un palco de muertes, se convirtió en un espacio para la catarsis colectiva del dolor de las madres, los familiares y la comunidad. 


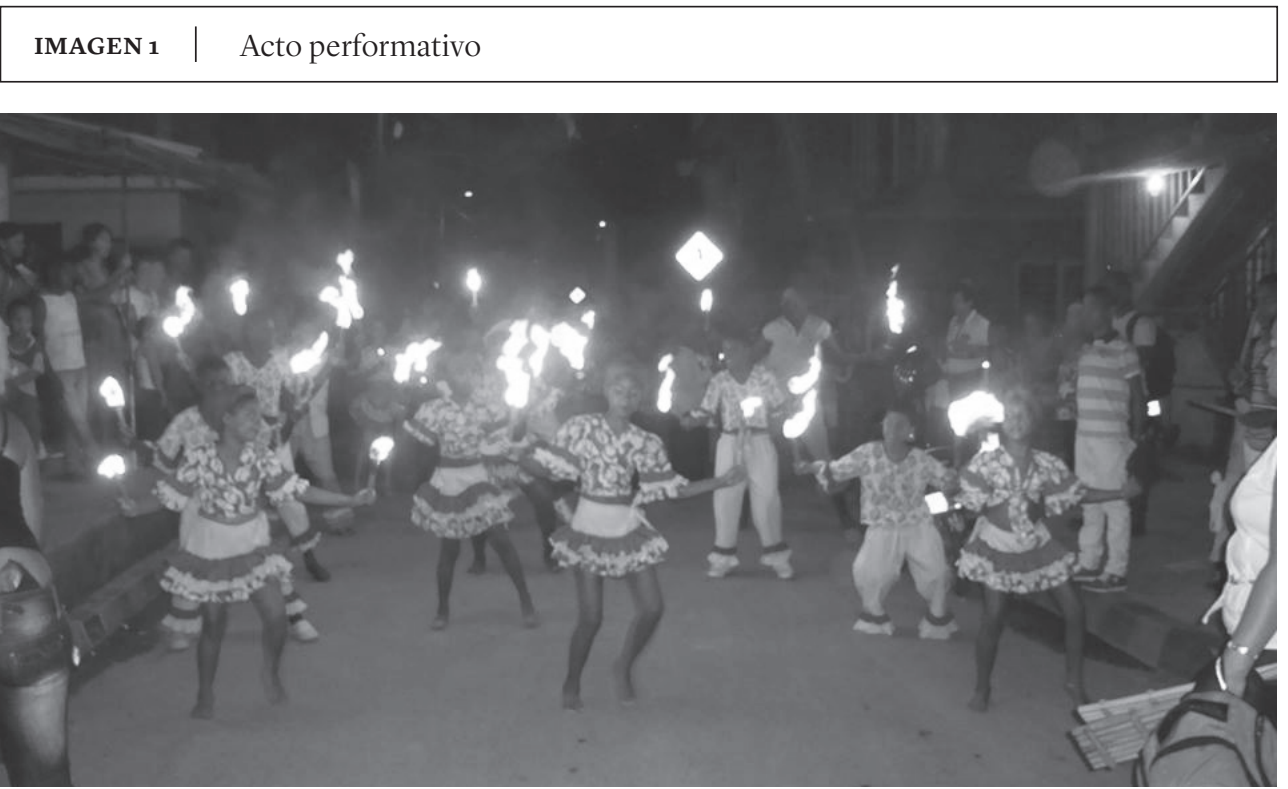

Foto: Vicenta Moreno Hurtado y Debaye Mornan.

Liliana, mujer negra de aproximadamente 48 años, habitante en el DA desde 1984, madre de 3 hijos, uno de ellos asesinado entre la violencia de pandillas expresó así su dolor:

"A mí que hace 4 meses me mataron a mi hijo que no se metía con nadie, puedo dar testimonio de lo que significa el dolor de un hijo muerto, eso no se lo deseo a nadie, ese es un dolor muy duro, aunque yo no he podido llorar, siento un nudo en la garganta cada vez que me acuerdo de él, de todos modos voy a acompañar a la hija que dejó de año y medio.”

También los vecinos reclamaban a los asesinados en un gesto de solidaridad. La violencia, que por tantas veces destruyó lazos de vecindad, era ahora significada para construir comunidad, como recordó Leticia, una de las participantes:

"A mi hasta ahora no me han matado ningún familiar en esas peleas de pandillas, pero me ha tocado ver muchos muertos de esa forma en estos tiempos. En mis tiempos no se veía eso así, eso rara vez mataban a alguien y cuando aparecía algún muerto tirado, todo el mundo se asustaba, ahora a la gente no le importa matar y quedarse tranquilo, tenemos que cuidar a los muchachos sean hijos o familiares de uno o no, para que no sigan sucediendo tantos muertos.

Los niños y las niñas alrededor de las velas que iban encendiendo, una a una, expresaban el miedo de transitar las calles y algunos lugares del barrio, pero también 
manifestaban su esperanza, el deseo de paz en su comunidad y el repudio por las muertes de los jóvenes. Los jóvenes del parche, más reservados, se aproximaron para rendir homenaje a los amigos muertos de las fotografías del tendero. Hablaban entre ellos al frente de las fotografías, recomponiendo las historias de sus pares o amigos muertos, sus aventuras con ellos, sus personalidades, sus deseos; otros hacían cuentas acerca de cuántas veces se han salvado ellos mismos de la muerte, cuántos atentados han tenido, sus miedos, y sus alegrías. Al final del acto, fueron ellos quienes ayudaron a bajar el tendedero y entregaron las fotos a cada familia correspondiente. En un gesto inesperado de devolución a las madres del cuerpo simbólico de los que murieron.

La frase central del evento, “¿A quién le duelen nuestros muertos?”, es el aspecto que quisiéramos invitarles a reflexionar con nosotras. ¿Qué pasa con la gente negra que sus muertes no cuentan como tragedia en la violencia de este país? ¿Por qué nuestro dolor no produce conmoción social como las muertes de aquellos investidos del privilegio racial y de clase? Un ejemplo de esto es la reciente situación por la que atraviesa el pueblo de Kenya: después de la masacre de 148 estudiantes universitarios, el mundo no se cuestiona, no denuncia, ni se conmueve ante el genocidio, al contrario, el silencio es su única manifestación; mientras que en otros acontecimientos, como el asesinato de los 12 periodistas franceses del diario semanal Charlie Hebdo, sí se sintió la conmoción social: Yo soy Charlie Hebdo / yo soy Francia, eran las frases que se escuchaban desde la primera hora del día en el transporte público, la radio, los periódicos, la televisión: lo local dándole la vuelta al mundo; esos muertos si dolieron. Incluso líderes del mundo y presidentes de muchas naciones manifiestan su condolencia y generan acciones de solidaridad y apoyo a la causa.

\section{IMAGEN 2 Valla}

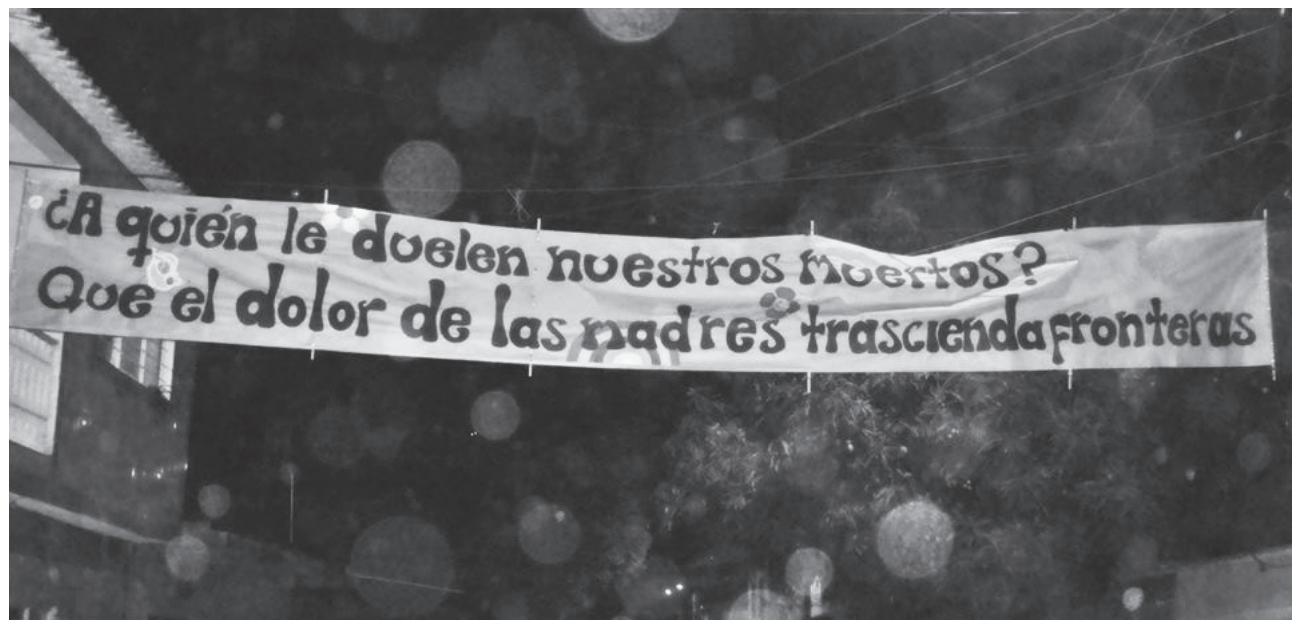

Foto: Vicenta Moreno Hurtado y Debaye Mornan. 
En otras palabras: ¿es posible politizar la muerte de la gente negra en un país donde la gente negra todavía pelea por su derecho a la vida y a ser persona? Las muertes prematuras, cuyas cifras aumentan año tras año y cuyos cuerpos yacen bajo los cementerios más pobres de la ciudad o bajo los caños de aguas residuales, en los buches de los gallinazos, en las fosas comunes o en los patios de las casas de pique, nos recuerdan que ¡No!

Bien se sabe que las estadísticas oficiales no registran todas las muertes violentas que sufren las comunidades en los sectores de las periferias; aun así las cifras oficiales ya son un llamado de alerta ante el genocidio programado entre nuestras comunidades. En el primer trimestre del 2013, el Observatorio de Cali registró 57 muertes violentas, sólo en la Comuna 13, ocho más que el primer trimestre del 2012. ${ }^{9}$ Sin embargo, Cali, la sucursal del cielo, parece indolente ante este consistente patrón de muertes prematuras; una de cuyas causas es la negligencia estatal: la falta de políticas públicas, parámetros de ordenamiento territorial, estructuras económicas, educativas, de salud y de seguridad pública. La producción política de la muerte: es decir, este patrón de muertes que no resultan del proceso natural de nacer, crecer, reproducirse y morir, es un índice que nos permite decir que en el Distrito de Aguablanca el racismo es una tecnología de dominación. Como algunos teóricos han mostrado, la muerte de la gente negra es producida por las vulnerabilidades sociales, resultado de decisiones políticas que privilegian a los estratos sociales más altos de la ciudad, los cuales están conformados mayoritariamente por comunidades blancas (Alves y Vergara, forthcoming).

La metrópolis de Cali, la ciudad con mayor cantidad de personas negras de Colombia, conserva estructuras coloniales de privilegios para unos y segregación, pobreza y muerte para otros. Nuestra invitación es a que leamos a la ciudad como un teatro de la dominación racial, construido por las estrategias políticas de gobernanza que eligen los cuerpos de la gente negra como el blanco de la muerte, y el cuerpo blanco (o no-negro) como el blanco de la protección estatal. ¿No es esta lógica racial la que orienta las políticas de seguridad ciudadana en nuestras ciudades? ¿Cuáles son las imágenes que nos vienen a la mente cuando pensamos en las geografías del miedo y de la delincuencia en Cali?

Los imaginarios urbanos del miedo son imaginarios racializados (Deávila, 2008). Orientan las acciones de la policía, las narrativas de la criminalidad, las inversiones estatales y las producciones académicas. Son los cuerpos negros desvalorizados, empobrecidos, estigmatizados en los medios masivos de comunicación y en narrativas académicas, mostrados/imaginados como holgazanes, criminales, violentos, poco inteligentes, vulgares, antimorales y desorganizados.

A las mujeres negras, madres de los jóvenes segregados en las cárceles, muertos en las fronteras invisibles entre las dinámicas del narcotráfico y del paramilitarismo, o azotados públicamente por la agencia policial, a ellas es a quienes más les duelen estos muertos (ver imagen 3). 
A pesar de todo, como ha mostrado Veena (2001), la violencia también construye comunidades políticas: en el caso de las mujeres del Distrito de Aguablanca, la violencia produce una comunidad imaginada por medio del dolor. Pero ellas no se quedan en el dolor, sino que a partir de él crean estrategias diversas para enfrentar a la violencia, para dignificar y proteger el cuerpo de sus hijos, compañeros, familiares y vecinos. Así se duelen de sus muertos.

\begin{tabular}{|l|l|} 
IMAGEN $_{3}$ & Valla \\
\hline
\end{tabular}

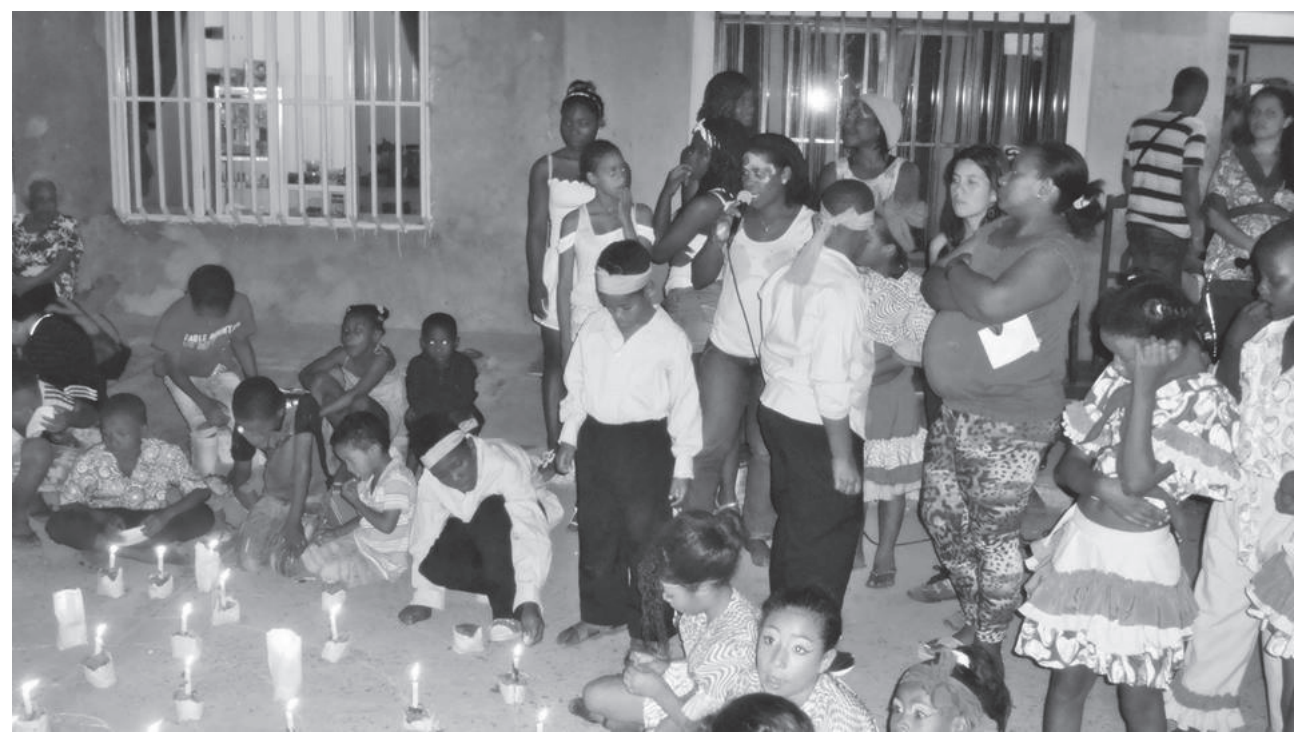

Foto: Vicenta Moreno Hurtado y Debaye Mornan.

\section{Desplazadas: dominación de género y racismo en la ciudad}

Las mujeres negras del Distrito de Aguablanca no sufren la violencia solamente como una experiencia secundaria, es decir, como un producto de la muerte de sus hijos. Decir eso es ignorar la experiencia autónoma producida en sus encuentros personales con la muerte, porque la muerte no es solamente una experiencia biológica. Las mujeres negras mueren varias veces por medio del proceso continuo y disimulado de negación del derecho a la ciudad, a la vivienda, a la subjetividad. Teresa Angulo, una mujer negra de 56 años, madre cabeza de familia, con dos hijas mujeres y un hijo hombre, desplazada del Pacífico colombiano, nos cuenta su experiencia con la muerte. Ella nos llama para contemplar su muerte simbólica: desterrada, lanzada a la ciudad cruel sin empleo, con la casa al hombro, como lo expresa la película. ${ }^{10}$ 
"Yo me vine de Tumaco una vez que se formó un traque traque... estaban matando a todo el mundo en el campo. Yo recogí a mis hijos y me vine embarcada por la noche. Cuando llegué a Cali me di cuenta que venía con la ropa de trabajar en el campo, y cuando voy a sacar lo que había empacado... todo era ropa de trabajo. ¿Se pueden imaginar a un andando acá como pordiosera?... ipero cuando a uno le toca, le toca! Porque yo no me iba a dejar matar. Yo para allá no vuelvo más porque eso está muy feo y además lleno de paisas"."

Aunque la academia colombiana lo tenga criminalmente silenciado, el destierro es una de las expresiones más brutales del racismo en este país. No solamente por las tragedias urbanas que provoca, sino también por la reproducción de una experiencia traumática para la gente negra: la trata desde África (Vergara, 2011). El destierro es la segunda trata. Secuestra cuerpos negros, los explota en la ciudad, los segrega en las laderas y los barrios marginales, los mutila, los asesina en la violencia homicida y los bota a los vertederos. 520 años después, en Colombia, uno de los países de América con mayor reconocimiento por su "constitución política incluyente", las comunidades negras sufren el destierro para dar "paso al progreso" y al dominio de las multinacionales, a las rutas de tráfico de drogas y al posicionamiento territorial de la oligarquía. El destierro no puede ser comprendido sin considerar el dominio patriarcal del cuerpo negro en la constitución de América. El cuerpo de la mujer negra es "sitio" donde las manifestaciones del dominio patriarcal encuentran su mayor expresión. Si el cuerpo masculino negro es casi siempre destrozado por los aparatos de la guerra, las mujeres son botines de los apetitos sexuales voraces de los hombres, quienes ejercen dominio sobre sus cuerpos, cosificándolas, matándolas, violándolas, igual que en épocas de la colonia. Sus cuerpos también son explotados en la servidumbre doméstica, en los empleos precarios de las calles, en las economías del turismo sexual en la costa marítima colombiana.

Teresa, al igual que muchas otras mujeres desterradas, llegó a Cali en 2005 en busca de protección, escapando de la muerte, protegiendo a sus hijos e hijas. A pesar de que nunca antes había estado en Cali, la lógica establecida por la ciudad la llevó a uno de los sitios predeterminados para las personas negras que vienen con la misma realidad, el Distrito de Aguablanca. Allí vive hasta el momento, en "Playa Baja”, un asentamiento de estrato social o de la comuna 13, que carece de servicios públicos, la vivienda es de estera y piso de tierra, permanentemente se presentan enfrentamientos entre pandillas y no se puede salir a determinadas horas del día.

Otro aspecto de esta relación de subordinación es el cinismo cruel de las elites locales. El cinismo se expresa no solamente en manifestaciones explícitas como armados o en busca de nuevas oportunidades de vida.

11. Tomado de la entrevista realizada a Teresa Angulo realizada por el grupo de investigación Interseccionalidades. Cali. Diciembre de 2013 . 
los anuncios de empleo que prefieren las mujeres de "buena apariencia" para los mejores puestos, sino también en los discursos públicos que niegan la existencia del racismo. En un conversatorio acerca de la discriminación racial y las posibilidades de vida digna que Cali ha dado a las mujeres negras, Camilo, un hombre que se autodenominó como raizal de la ciudad, manifestó: "Ustedes los negros deberían estar agradecidos con Cali porque les ha abierto sus puertas, albergando a todos los que llegan de allá del Pacífico."

En el discurso de Camilo se puede identificar parte de las narrativas que describen a Cali como una ciudad acogedora y libre de racismo; pero ¿cuál es el lugar social que ocupan los y las negras en la ciudad? Tendríamos que revisar lo que significa ser ciudadanos en una metrópolis como Cali, donde la mayoría de negros y negras ocupan un estatus de ciudadanos de tercera categoría o de no-ciudadanos. ¿Por qué tendrían que estar agradecidas las mujeres negras que han llegado desterradas en diferentes oleadas desde 1940 a esta ciudad? ¿Por la segregación en las geografías de la muerte? ¿Por la explotación en las cocinas de las elites o en las fábricas de textiles? ¿Por la falta de posibilidades educativas, de salud y autonomía? ¿Por la muerte prematura de sus hijos?

Las mujeres negras que habitan en Cali, bien sean raizales o que hayan llegado en las diferentes oleadas históricas, han tenido que resistir distintos maltratos de la Policía Antimotines, de las élites blancas de la ciudad, quienes las han arrinconado en los últimos lugares, casi afuera de la metrópolis para que no "afeen" la Cali bella, la Cali mestiza. Un ejemplo concreto del lugar "social" reservado a los negros y negras en Cali son las políticas de vivienda establecidas por el Gobierno. En Cali, espacios como Potrero Grande, África, Haití, no son solamente nombres “creativos" de localidades; ellos revelan la estructura racial del espacio urbano y la producción calculada y disimulada de políticas públicas pobres para los pobres. Potrero Grande, por ejemplo, es una supuesta urbanización que consumió millones de pesos colombianos en un proyecto de vivienda que desde el nombre hasta la estructura física le asigna un lugar inhumano a las y los desterrados.

Parafraseando a Santiago Arboleda (1998), se podría decir que es la oligarquía blanco-mestiza de Cali quien debería estar agradecida de la llegada de las comunidades negras, ya que su presencia masiva le permitió a la ciudad ascender al tercer puesto en nivel de progreso e industrialización nacional. Esto se explica por dos motivos: primero porque al acrecentar la población, se adquirió la connotación de ciudad grande; segundo porque las elites blanco-mestizas aprovecharon para emplear mano de obra barata fortaleciendo sus capitales a costa de la explotación del cuerpo negro. Por tanto, a pesar de que los negros y negras han construido la ciudad, el progreso político y económico de Cali sigue en las manos de las familias tradicionales de origen español. Esa dinámica histórica de dominación en el espacio urbano nos permite leer a Cali como una ciudad 
construida por el proceso a que David Harvey (2003) ha llamado muy apropiadamente de "acumulación por desposesión”. Pero, yendo más allá de los planteamientos de Harvey, queremos llamar la atención en la simbiosis entre raza, clase y género en la producción de la ciudad.

En sus análisis acerca de la ciudad, Harvey propone elementos importantes para entenderla como un espacio donde se tejen relaciones de poder que evidencian la desigualdad en términos de derechos, produciendo geografías de dominación y geografías de resistencia. En este sentido, nuestras experiencias arrojan que, además de una condición de pobreza, en términos de ocupar una posición en una clase no privilegiada, los elementos raciales y de género son factores fundamentales que agudizan la marginalización de las mujeres negras; pero a su vez se convierten en componentes políticos para la reconstrucción de subjetividades resistentes. En una conversación con Liliana (a quien ya describimos anteriormente), ella cuenta:

\footnotetext{
"Yo cada vez que veo las fotos de mi hijo pienso que él está vivo, todavía yo no lo asimilo. Pero esto no solamente me sucede a mí, sino a muchas de las mujeres que les han matado sus hijos, yo pienso que es importante que en el barrio se nos hagan talleres de Derechos Humanos, para aprender a defendernos de la violencia."
}

Después del asesinato de su hijo fue una de las mujeres que ayudó en la organización del acto performático de A quién le duelen nuestros muertos, Liliana se empieza a vincular más a procesos organizativos de su sector, como la Asociación Casa Cultural El Chontaduro y la Junta de Acción Comunal. Muchas de las mujeres no solo se quedan sumergidas en el dolor, sino que esas condiciones de violencia y segregación las lleva a construir alternativas para transformar dichas situaciones. Es así como Liliana empieza a actuar de una manera más política, reconociendo que tiene derecho a la formación, y reconociendo su papel social dentro de la comunidad

\section{Triple Discriminación}

En medio de todas estas dinámicas las mujeres han sufrido la triple discriminación a la que se refieren las activistas afro-feministas: por ser mujeres, negras y pobres. Ellas (nosotras) son únicamente vistas como máquinas de producción de riqueza o como objeto sexual para los placeres masculinos (Collins, 1999; Curiel, s.f.). La subordinación de las mujeres negras en el empleo doméstico en Cali es vista como algo natural. El relato de Cornelia muestra cómo esta subordinación es parte de la experiencia femenina negra desde temprana edad: 


\begin{abstract}
"Yo estoy trabajando como empleada doméstica desde los 14 años. Durante ese tiempo he trabajado en tres restaurantes. Actualmente estoy trabajando en uno de ellos. En ninguno me he ganado ni siquiera el mínimo ni he tenido prestaciones de servicios ni nada de eso. Si a mí me dijeran que trabajara como jefe de cocina ¡ve! ¡Yo de una me iría! ¿Sabe qué me gustaría? Conseguir un trabajo donde tuviera todo, liquidación, prestación, seguro, aunque el seguro no me preocupa mucho porque hay mucha gente que se ha quedado sin Sisben, y cuando se queda sin trabajo se queda a la intemperie, sin nada.”
\end{abstract}

La mayoría de las mujeres negras del Distrito de Aguablanca, son “exprimidas" desde niñas en las casa de élites de la ciudad, desde allí han criado y alimentado a empresarios, doctores, políticos y demás personajes de las clases altas a cambio de salarios de hambre que no les permiten el sustento diario ni la crianza de sus hijos. En esta ecuación perversa, ellas cuidan de los hijos de la élite mientras sus propios hijas e hijos están destinadas a la misma trayectoria de vida o sometidos a la lógica de la violencia urbana.

El Estado racial y patriarcal ha imperado de manera brutal sobre el cuerpo de las mujeres negras negando posibilidades de salud, oportunidades educativas y económicas además de patrocinar la explotación y manipulación del mercado laboral, el narcotráfico y las dinámicas de guerra que las afectan de sobremanera. Estas dinámicas de la violencia, que tienen al cuerpo femenino negro como su blanco, ilustran cómo raza, género y clase social se intersectan en la producción de patrones de vulnerabilidad social. Esto equivale a decir que ningún análisis de la violencia puede prescindir de la intersección de las distintas categorías políticas que sustentan los regímenes de poder en nuestra sociedad. Como plantea Avtar Brah: "el análisis interseccional explora cómo los diferentes ejes de diferencia se articulan en niveles múltiples y crucialmente simultáneos en la emergencia de modalidades de exclusiones, desigualdad y formación de sujetos específicos en un contexto." (2013:16).

\title{
Conclusiones
}

El mito de Colombia como sociedad sin racismo sostiene que a partir de 1853 los negros pasaron a ser ciudadanos como todos los demás, y que por eso seguir hablando de racismo no es más que expresiones de resentimiento y victimización. Sin embargo, la experiencia de las mujeres negras, envejeciendo en las cocinas de las élites caleñas es una fuerte evidencia de la persistencia de una relación colonial que organiza el vivir urbano de la gente negra. Negar la relación directa del racismo y la discriminación de género en la configuración de las vulnerabilidades sociales a que mujeres negras y hombres negros están sometidos, no solamente es una ignorancia deliberada, sino también un indicativo de cómo la sociedad colombiana despolitiza la categoría raza 
mientras reproduce el privilegio racial. Eso no quiere decir que las personas negras son simples víctimas del racismo.

En busca de autonomía y mejores condiciones de vida, las mujeres negras han generado diversas estrategias económicas, desde el rebusque transgreden las normas estatales que les exigen pagos de impuestos sin tener en cuenta las condiciones diferenciales de sus realidades, hasta el rechazo a ser sometidas a la explotación en el empleo doméstico. Natividad, mujer negra del Distrito de Aguablanca de Cali, nos cuenta por qué se niega a ser explotada en las casas de las familias tradicionales:

"Yo prefiero vender que trabajar en casas de familia porque me va mejor. Ahora que se están complicando las cosas con el MIO, me gustaría tener otro trabajo. Además yo he visto cómo el lobo le quita las cosas a otros vendedores iy no se las devuelven! Por eso nosotros nos hemos asociado a una cooperativa que se llama Vendedores Independientes del Valle del Cauca, eso le dan a uno un chaleco y con eso lo dejan de molestar". ${ }^{12}$

La experiencia urbana de mujeres como Natividad da cuenta de la capacidad creadora para transformar las geografías de la pobreza y la muerte en posibilidades de una vida urbana más asequible. Sea en los actos performáticos o en símbolos de la herencia africana como los alabaos o en el rebusque... las mujeres negras subvierten las lógicas espaciales de opresión y diseñan posibilidades para una lucha política por el derecho a la ciudad. Por tanto, ellas son agentes políticos que permanentemente movilizan sus comunidades contra las dinámicas de guerra y luchan por darle otros sentidos a su territorio urbano, trascendiendo las fronteras invisibles impuestas por los actores armados. Ojalá podamos no solamente aprender sobre sus experiencias, sino también a luchar en contra de las dinámicas de la violencia que siguen devorando los cuerpos negros.

\section{Referencias}

ALVES, JAIME \& VERGARA, AURORA. (s.f.). “The Brunch of Paradise: Geographies of Privilege, Multiculruralism and Black Social Suffering in Cali, Colombia”. Urban Geography (forthcoming).

ALVES, JAIME (2014). "From Necropolis to Blackpolis: Necropolitical Governance and Black Spatial Praxis in São Paulo, Brazil". Antipode, 46(2), 323-339.

ARBOLEDA, SANTIAGO. (2007). Conocimientos ancestrales amenazados y destierro prorrogado: la encrucijada de los a frocolombianos. Bogotá, Universidad Nacional de Colombia.

ARBOLEDA, SANTIAGO. (1998). Le dije que me esperaray Carmela no me esperó. El Pacífico en Cali. Universidad del Valle. Cali, Colombia 
CARNEIRO, SUELI, Y CRISTIANE, CURY. (1990) “O poder feminino no culto aos orixás.” Revista de Cultura Vozes, pp 157-79.

COLLINS, P. H. (1999). Black feminist thought: Knowledge, consciousness, and the politics of empowerment. Routledge.

DEÁVILA, O. (2008). Construyendo sospechas: imaginarios del miedo, segregación urbana y exclusión social en Cartagena 1956-1971. Cuadernos de Literatura del Caribe e Hispanoamérica, 7,35-50.

HARVEY, D. (2003). “The right to the city”. International Journal of Urban and Regional Research, 27(4), 939-941.

LEFEBVRE, H. (1969). “El derecho a la ciudad”. Edicion 62 S.S. Barcelona, España

LUGONES, M. (2011). “Hacia un feminismo descolonial”. En La manzana de la discordia. 6(2), 105-119.

POSSO, J. (2008). "Mecanismos de discriminación étnico-racial, clase social y género: la inserción laboral de mujeres negras en el servicio doméstico de Cali”. Pobreza, exclusión social y discriminación étnico-racial en América Latina y el Caribe, pp. 215-240.

VEENA, DAS. (2001). Lenguajes, Subjetividades y Experiencias de Violencia. Pag. 14- 21.

VERGARA FIGUEROA, AURORA. (2011). Ripped from the Land, Shipped Away and Reborn: Unthinking the Conceptual and Socio-Geo-Historical Dimensions of the Massacre of Bellavista. [Masters Theses]. Paper 570. Consulta realizada desde: http://scholarworks.umass.edu/ theses/570

\section{Webgrafía}

BRAH, A. (2013). Pensando en y a través de la interseccionalidad. Lateinamerika-Institut der Freien Universität Berlin. http://www.academia.edu/6444540/Interseccionalidad_y_diversidad._En_ defensa_de_un_modelo_de_analisis_categorial_no_opresivo_que_respeta_la_diferencia (Consultado el 27 de febrero de 2015).

CURIEL, O. (s.f.). Género, raza, sexualidad; debates contemporáneos. http://www.urosario.edu. co/urosario_files/1f/1fid1951-of7e-43ff-819f-ddo5e5fedo3c.PDF (Consultado el 20 de febrero de 2015).

EL ESPECTADOR (2014). “¿Cuál es la cuidad con más empleadas domésticas internas en Colombia?”. En ElEspectador. http://www.elespectador.com/noticias/infografia/cual-cuidadmas-empleadas-domesticas-internas-colombia-articulo-493159 (Consultado el 20 de febrero de 2015).

URREA, F. ET. AL. (2011). Pobreza y exclusión social en Cali. Un análisis de los hogares 
y la población de sectores populares y clases medias bajas a través del SIISAS 2009.

http://planeacion.cali.gov.co/Publicaciones/Inclusion\%2Osocial/Pobreza\%2Oy\%2oexclu sion\%2Osocial\%2oen\%20Cali.pdf (Consultado 2 de mayo de 2015). 